\title{
Dissolution of metals by human and rabbit alveolar macrophages
}

\author{
MARGOT LUNDBORG,' A EKLUND, ${ }^{3}$ B LIND, ${ }^{2}$ AND P CAMNER ${ }^{14}$ \\ From the Sections of Inhalation' and Inorganic Toxicology, ${ }^{2}$ Department of Toxicology, National Institute of \\ Environmental Medicine, Department of Thoracic Medicine, ${ }^{3}$ Karolinska Hospital, and Department of \\ Environmental Hygiene, ${ }^{4}$ Karolinska Institute, S-104 01 Stockholm, Sweden
}

\begin{abstract}
The ability of human and rabbit alveolar macrophages to dissolve $0 \cdot 1-0.5 \mu \mathrm{m} \mathrm{MnO}_{2}$ particles in vitro was compared. The amount of $\mathrm{Mn}$ added and dissolved from the particles over periods of nought, one, and three days was determined by flame atomic absorption spectrophotometry. The amount dissolved by human and rabbit macrophages was similar; on average 43.1\% and $43.9 \%$, respectively, were dissolved within three days. But rabbit and human macrophages dissolved significantly more Mn than was dissolved in the respective culture medium without macrophages after one and three days. It is suggested that the dissolution of particles by alveolar macrophages should be one basic component in any model of alveolar clearance of inorganic particles.
\end{abstract}

Recent experimental studies in man have shown that clearance of whole particles deposited in the alveolar part of the lung is .a slow process; most of the particles clear with a half time of about one or several years. ${ }^{1-2 a}$ The slow clearance of whole particles increases the importance of investigating the dissolution of particles in the lung. Even particles that are usually considered insoluble are dissolved in the lung. ${ }^{3-6}$ Although the alveolar macrophages phagocytose particles deposited in the alveoli, the ability of the macrophages to dissolve metal particles has not been measured quantitatively until recently.

Lundborg et al incubated samples of rabbit alveolar macrophages for nought to five days with $\mathrm{MnO}_{2}$ particles and estimated the amount of Mn which then dissolved. ${ }^{7}$ The macrophages dissolved two to three times more Mn than the culture medium. The aim of the present study was to investigate whether human macrophages also have this ability to dissolve $\mathrm{MnO}_{2}$ particles.

\section{Material and methods}

\section{DESIGN}

Human alveolar macrophages were lavaged from

Received 12 November 1984

Accepted 7 January 1985 eight volunteers. Alveolar macrophages were also lavaged from six apparently disease free male rabo bits, weight $2-3 \mathrm{~kg}$. On each day that human mace rophages were lavaged (one or two subjects), mac rophages were also lavaged from one rabbit.

The macrophages were incubated with $\mathrm{MnO}_{2}$ particles, and the amount of $\mathrm{Mn}$ in soluble and in particulate form was measured after nought, one, and three days using conventional flame atomic absorption spectrophotometry (AAS). For each experiment with a sample of macrophages and $\mathrm{MnO}_{2}$ particles a control experiment without macrophages was performed to study the dissolution of the $\mathrm{MnO}_{2}$ particles in the medium.

\section{HUMAN TEST SUBJECTS}

Table 1 gives the personal data of the eight volunteers. Subject 1 underwent fibreoptic bronchoscopy because he had a left upper lobe infiltrate. After treatment with antibiotics, which started before the bronchoscopy, the infiltrate dissolved. In the other subjects the bronchoscopy was not performed $N$ because of clinical indications. All these subjects had normal chest $x$ ray pictures. Subjects 2,6 , and 7 had a history of allergic rhinitis and subject 3 of $\underset{\omega}{N}$ asthmatic bronchitis, but none had any symptoms at $\underset{\sigma}{\sigma}$ the time of bronchoscopy. All eight subjects had 0 normal bronchial mucosa except for a slight redness in some of the smokers. 
Dissolution of metals by human and rabbit alveolar macrophages

Table 1 Personal and lavage data of volunteers

\begin{tabular}{|c|c|c|c|c|c|c|c|c|c|c|}
\hline \multirow[t]{2}{*}{ Patient No } & \multirow[t]{2}{*}{ Sex } & \multirow[t]{2}{*}{ Age } & \multicolumn{2}{|c|}{ Smoking habits } & \multirow{2}{*}{$\begin{array}{l}F E V_{1} \\
\text { (\% pred) }\end{array}$} & \multirow{2}{*}{$\begin{array}{l}\text { FVC } \\
\text { (\% pred) }\end{array}$} & \multirow{2}{*}{$\begin{array}{l}\text { Lavage volume } \\
(m l)\end{array}$} & \multirow{2}{*}{$\begin{array}{l}\text { Recovered } \\
\text { fuid }(\mathrm{ml})\end{array}$} & \multirow{2}{*}{$\begin{array}{l}\text { Total cell yield } \\
\left(\times 10^{\circ}\right)\end{array}$} & \multirow[t]{2}{*}{ Lymphocytes (\%) } \\
\hline & & & Cig/day & $\begin{array}{l}\text { Duration } \\
\text { (years) }\end{array}$ & & & & & & \\
\hline $\begin{array}{l}1 \\
2 \\
3 \\
1 \\
5 \\
5 \\
7 \\
3\end{array}$ & $\begin{array}{l}\mathbf{M} \\
\mathbf{F} \\
\mathbf{F} \\
\mathbf{F} \\
\mathbf{F} \\
\mathbf{F} \\
\mathbf{M} \\
\mathbf{M}\end{array}$ & $\begin{array}{l}62 \\
25 \\
24 \\
22 \\
21 \\
19 \\
23 \\
30\end{array}$ & $\begin{array}{l}0^{*} \\
5 \\
1-10 \\
1-5 \\
10-15 \\
15 \\
0 \\
10\end{array}$ & $\begin{array}{r}- \\
6 \\
7 \\
7 \\
6 \\
8 \\
0 \\
12\end{array}$ & $\begin{array}{r}98 \\
112 \\
115 \\
94 \\
88 \\
89 \\
87 \\
103\end{array}$ & $\begin{array}{r}92 \\
102 \\
102 \\
102 \\
87 \\
88 \\
84 \\
97\end{array}$ & $\begin{array}{l}250 \\
220 \\
200 \\
200 \\
100 \\
300 \\
300 \\
300\end{array}$ & $\begin{array}{r}180 \\
140 \\
150 \\
135 \\
55 \\
210 \\
190 \\
220\end{array}$ & $\begin{array}{r}14 \cdot 0 \\
25 \cdot 5 \\
33.0 \\
15 \cdot 6 \\
20.0 \\
34 \cdot 0 \\
8.3 \\
21.0\end{array}$ & $\begin{array}{r}- \\
3.0 \\
7 \cdot 5 \\
11.7 \\
6.5 \\
9.8 \\
15.3 \\
7.3\end{array}$ \\
\hline
\end{tabular}

* Ceased five years ago.

$\mathrm{MnO}_{2}$ PARTICLES

$\mathrm{MnO}_{2}$ powder (Mallinckrodt, min 99.5\% $\mathrm{MnO}_{2}$ ) was suspended in deionised water. After 10 minutes of ultrasonic treatment the larger particles were allowed to sediment for 10 minutes. The water containing the smaller particles was then removed and centrifuged at $800 \mathrm{~g}$ for 10 minutes. The particles in this precipitate were then used for all the solubility experiments. Most of these particles were about one tenth or a few tenths of a $\mu \mathrm{m}$, only $4 \%$ were larger than $0.4 \mu \mathrm{m} .^{7}$ Before the particles were used they were heated for 30 minutes at $80^{\circ} \mathrm{C}$.

\section{MACROPHAGES}

The human macrophages were lavaged from the right middle lobe using a modification of the method of Hoslam et al. ${ }^{8}$ A saline solution buffered to $\mathrm{pH}$ 7.0 with sodium bicarbonate was introduced and immediately gently aspirated again. The fluid was collected in a container kept on ice. The volume introduced ranged from 100 to $300 \mathrm{ml}$ (table 1). The rabbit macrophages were lavaged with the same solution as that used for the human macrophages but otherwise were treated as described earlier. 910

The macrophage suspensions were centrifuged at $300 \mathrm{~g}$ for 10 minutes at room temperature and resuspended in $5 \mathrm{ml}$ Hank's solution. The cell concentration was then estimated in a Bürker chamber. After a second centrifugation the cells were resuspended in Hank's solution and $0.4 \mathrm{ml}$ samples were then placed on cover glasses and inserted into Leighton tubes. The cells were allowed to adhere for 20 minutes after which $2 \mathrm{ml}$ of medium was added. The medium consisted of $15 \%$ serum and Hepes buffered Parker solution ( $\mathrm{pH} \mathrm{7.4)} \mathrm{and} \mathrm{contained} 100$ IU bensylpenicillin/ml and $100 \mu \mathrm{g}$ streptomycin sulphate/ml. For the tubes with human macrophages, human serum (A B, Rh-Sabbatsberg's Hospital) was used and for the tubes with rabbit macrophages, rabbit serum (The National (Swedish) Bacteriological Laboratory). The Leighton tubes were placed in an incubator (ASSAB T $304 \mathrm{G}$ ) at $37^{\circ} \mathrm{C}, 5 \% \mathrm{CO}_{2}$ and $80 \%$ relative humidity for one hour. The medium was then decanted. From the number of cells added to the Leighton tubes and a count of the number of cells in the decanted medium the number of remaining cells was estimated to be $1.9 \pm 0.4 \times 10^{6}$ (mean \pm SD) for the human macrophages and $1.9 \pm 0.5 \times 10^{6}$ for the rabbit macrophages. Further $2 \mathrm{ml}$ of fresh medium and the $\mathrm{MnO}_{2}$ particles were then added to the tubes and the sample returned to the incubator. Parallel to each macrophage experiment a control experiment using the same medium and the same procedure but without macrophages was performed.

After nought, one, and three days the medium was removed and $1 \mathrm{ml} 0.25 \%$ trypsin solution was added to each tube including the controls. After another 30 minutes in the incubator the tubes were placed in a vibrator for a few seconds. The contents of the Leighton tubes were then removed. Another $1 \mathrm{ml}$ trypsin solution was added to the tubes and removed after 10 minutes. The removed contents of the tubes including $2 \mathrm{ml}$ trypsin solution were mixed and centrifuged for about 10 minutes at $350 \mathrm{~g}$. Half a millilitre of $1 \%$ Triton- $X$ solution was added to the precipitate which was then treated ultrasonically for 40 minutes to disintegrate the cells. The precipitate and supernatant were then mixed and filtered through a $0.22 \mu \mathrm{m}$ Millipore filter (type GS). The amount of $\mathrm{Mn}$ in the filter was taken to represent the amount of $\mathrm{Mn}$ in particulate form and the amount in the filtrate was taken to represent the amount in soluble form.

\section{Mn ANALYSIS}

All glassware and plastic tips were carefully washed with $10 \%$ nitric acid and rinsed several times with deionised water before use. Chemicals were of pro analysi quality (Merck). The filters were wet digested in glass beakers $(50 \mathrm{ml})$ with $2 \mathrm{ml}$ of a mixture of concentrated nitric acid and perchloric acid $\left(\mathrm{HNO}_{3}: \mathrm{HCLO}_{4} 1: 1\right)$ on a boiling waterbath for 20 minutes. Deionised water was added to an 
Table 2 Human and alveolar macrophages were incubated with $\mathrm{MnO}_{2}$ particles at $37^{\circ} \mathrm{C}$ for nought, one, and three days, whereafter ${ }^{\text {the }}$ amounts of Mn added and dissolved were estimated. Parallel to each macrophage sample a control without macrophages was tested. (Ra are expressed as mean $\pm S D)$

\begin{tabular}{|c|c|c|c|c|c|c|c|c|c|}
\hline & \multicolumn{3}{|l|}{0 days } & \multicolumn{3}{|l|}{1 day } & \multicolumn{3}{|l|}{3 days } \\
\hline & $\begin{array}{l}\text { Mn added } \\
(\mu g)\end{array}$ & $\begin{array}{l}\text { Mn dissolved } \\
(\mu g)\end{array}$ & $\begin{array}{l}\text { Mn dissolved } \\
(\%)\end{array}$ & $\begin{array}{l}\text { Mn added } \\
(\mu g)\end{array}$ & $\begin{array}{l}\text { Mn dissolved } \\
(\mu g)\end{array}$ & $\underset{(\%)}{M n}$ dissolved & $\begin{array}{l}\text { Mn added } \\
(\mu g)\end{array}$ & $\begin{array}{l}\text { Mn dissolved } \\
(\mu g)\end{array}$ & $\underset{(\%)}{M n}$ dissolve \\
\hline $\begin{array}{l}\text { Human macrophages } \\
\qquad(\mathrm{n}=8)\end{array}$ & $7 \cdot 1 \pm 3.6$ & $0.4 \pm 0.2$ & $6.0 \pm 2.9$ & $9 \cdot 2 \pm 6.0$ & $1.6 \pm 0.6$ & $20.7 \pm 6.8$ & $9 \cdot 1 \pm 3.5$ & $3.9 \pm 1.8$ & $43 \cdot 1 \pm 7 \cdot 2$ \\
\hline $\begin{array}{l}\text { Human controls } \\
\qquad(n=8)\end{array}$ & $10 \cdot 7 \pm 6 \cdot 5$ & $0.4 \pm 0.2$ & $4 \cdot 5 \pm 1 \cdot 5$ & $11 \cdot 2 \pm 7 \cdot 3$ & $1 \cdot 2 \pm 0.7$ & $11 \cdot 9 \pm 4 \cdot 7$ & $11.5 \pm 4.9$ & $2.6 \pm 0.9$ & $25 \cdot 3 \pm 7 \cdot 8$ \\
\hline $\begin{array}{l}\text { Rabbit macrophages } \\
(n=6)\end{array}$ & $7.3 \pm 3.9$ & $0.3 \pm 0.2$ & $4.9 \pm 1.9$ & $7.9 \pm 3.6$ & $1.6 \pm 0.7$ & $22.8 \pm 9.5$ & $9 \cdot 1 \pm 4 \cdot 1$ & $4 \cdot 0 \pm 2 \cdot 0$ & $43.9 \pm 9.3$ \\
\hline $\begin{array}{l}\text { Rabbit controls } \\
(n=6)\end{array}$ & $9 \cdot 1 \pm 4 \cdot 6$ & $0.3 \pm 0.2$ & $3.9 \pm 2.7$ & $7 \cdot 5 \pm 4 \cdot 0$ & $0.5 \pm 0.3$ & $6.9 \pm 2.5$ & $9 \cdot 0 \pm 5.2$ & $1.6 \pm 1.0$ & $16.9 \pm 5.0$ \\
\hline
\end{tabular}

appropriate amount (about $22 \mathrm{~g}$ ). The filtrate was analysed without pretreatment against diluted standards. The manganese concentration in the solutions was determined by AAS, using a deuterium background correction (Perkin Elmer, model 403). All chemicals and materials used for the macrophage experiment, including the macrophages and the bronchoscopic equipment, were tested for manganese and were found to be in the order of the detection limit of the method or below. For details see Lundborg et al. ${ }^{7}$

\section{STATISTICAL ANALYSIS}

Paired $t$ test was used to compare the macrophages and their controls and unpaired $t$ test was used to compare human and rabbit samples without prediction of direction.

\section{Results}

Table 2 shows the amounts of Mn added to the human and rabbit macrophage samples and their controls. The dissolved $\mathrm{Mn}$ both in $\mu \mathrm{g}$ and in percentage of the added amount is also shown. In the one day and three day samples the added amounts are similar for the four experimental conditions with the exception that the human controls received more Mn than the other three conditions. The human controls received significantly more $\mathrm{Mn}$ than the human macrophages in both the one day and three day samples $(p<0.05)$.

When dissolved $\mathrm{Mn}$ in the human macrophages and human controls was compared the difference was statistically significant; for $\mu \mathrm{g}$ dissolved the $\mathrm{p}$ values were $<0.01$ and 0.02 for the one day and three day samples respectively, and for the percentage amount dissolved the corresponding $p$ values were $<0.05$ and $<0.002$. When the rabbit macrophages were compared with the rabbit controls both the $\mu \mathrm{g} \mathrm{Mn}$ and percentage $\mathrm{Mn}$ dissolved differed significantly in the one day and three day samples $(p<0.001)$.

When the human and rabbit controls were compared the $\mu \mathrm{g}$ Mn dissolved differed significantly in the one day samples $(p<0.05)$ and almost significantly in the three day samples $(0.05<p<0$ $0 \cdot 1)$. The dissolved $\mathrm{Mn}$ in percentage differed significantly both in the one day and three dafof samples $(p<0.05)$.

\section{Discussion}

The average amount of Mn added in the different experimental conditions was close to $10 \mu \mathrm{g}$ but there were large variations. In our earlier study we studied the dissolution of $\mathrm{Mn}$ added within the range of a few $\mu \mathrm{g}$ to about $100 \mu \mathrm{g}$. $^{7}$ Within this range the amount of $\mathrm{Mn}$ dissolved in $\mu \mathrm{g}$ increased with the amount added, whereas the per cent Mn dissolved decreased with the amount Mn added. To investigate whether this was also the case in the present study the correlation coefficients for the four experimental conditions in the one day and three day samples were calculated (table 3 ). The indi-

Table 3 Correlation coefficient (r) between Mn added in $\mu \mathrm{g}$ and $\mathrm{Mn}$ dissolved in $\mu \mathrm{g}$ and per cent

\begin{tabular}{|c|c|c|c|c|}
\hline & \multicolumn{2}{|c|}{ Dissolved Mn ( $\mu g)$} & \multicolumn{2}{|c|}{ Dissolved Mn (\%) } \\
\hline & 1 day & 3 days & 1 day & 3 days \\
\hline $\begin{array}{l}\text { Human macrophages }(n=8) \\
\text { Human controls }(n=8) \\
\text { Rabbit macrophages }(n=6) \\
\text { Rabbit controls }(n=6)\end{array}$ & $\begin{array}{l}+0.64 \\
+0.59 \\
+0.86 \\
+0.63\end{array}$ & $\begin{array}{l}+0.89 \\
+0.85 \\
+0.82 \\
+0.86\end{array}$ & $\begin{array}{l}-0.77 \\
-0.53 \\
-0.73 \\
-0.59\end{array}$ & $\begin{array}{l}+0.04 \\
-0.90 \\
-0.03 \\
-0.17\end{array}$ \\
\hline
\end{tabular}

Dissolved Mn (\%) 
vidual r-values are uncertain owing to the small numbers of samples. Nevertheless, the general pattern of positive $r$ values for dissolved $\mathrm{Mn}$ in $\mu \mathrm{g}$ and negative or very small positive $r$ values for dissolved $\mathrm{Mn}$ in per cent agrees with the earlier results. This implies that in the present study the differences between macrophages and controls were not due to differences in the amount of added Mn as those differences were found in dissolved $\mathrm{Mn}$ in $\mu \mathrm{g}$ as well as dissolved $\mathrm{Mn}$ in per cent. The amount Mn dissolved by the rabbit macrophages and then controls agrees well with our earlier results.' Human and rabbit macrophages dissolved $\mathrm{MnO}_{2}$ particles to a similar degree but more was dissolved in the human than in the rabbit controls. The only difference between the control samples was that they consisted of human or rabbit serum.

Lundborg $e t$ al suggested that the reason larger amounts of Mn were dissolved in the macrophage samples than in the control samples was because of the low pH values in the lysosomes.' In the lysosomes, $\mathrm{pH}$ values of $4-5$ have been reported in the -neutrophils and the peritoneal macrophages of rodents. $" 12$ This suggestion is supported by the fact that the amount of Mn dissolved in water at pH 6.5 was similar to the amount dissolved in the rabbit controls and that dissolution in water at $\mathrm{pH} \mathrm{4.0}$ was complete within three days. The $\mathrm{pH}$ in the phagosomes of human neutrophils has been reported to be $6 \cdot 0-6 \cdot 5 .{ }^{13}$ We surmised that human alveolar macrophages might have a lower capacity to dissolve manganese than those in the rabbit macrophages, but this was apparently not the case.

If it is assumed that the dissolved Mn leaves the macrophages and the lung at a rate that is more rapid than the dissolution rate our in vitro tests indicate a clearance of $\mathrm{MnO}_{2}$ particles from the lung with a half time of four days for both rabbits and man. This agrees fairly well with experiments in guinea pigs where the clearance of $\mathrm{MnO}_{2}$ particles occurred with a half time of about two days after the first two days after inhalation. ${ }^{14}$ The somewhat faster clearance found in intact animals might be caused by some impairment of our in vitro macrophages to dissolve the particles. After three days, macrophages lost their ability to dissolve the $\mathrm{MnO}_{2}$ particles more than the culture medium. ${ }^{7}$ Clearance of $\mathrm{MnO}_{2}$ particles in man has been estimated to be 65 days. ${ }^{15}$ As rather small particles (mass mean diameter $0.9 \mu \mathrm{m}$ ) were used in this study, and as probably less $\mathrm{MnO}_{2}$ per macrophage was given than in our in vitro study, the ability of the macrophages to dissolve $\mathrm{Mn}$ in vitro cannot explain the results. It is not known whether this discrepancy can be explained by physicochemical differences between the particles, or by the binding of dissolved Mn to proteins in the human lung. As particles are phagocytised by macrophages, however, and as macrophages have the ability to dissolve metals, we believe that a model of alveolar clearance of particles from the lung must include the dissolution of the particles by alveolar madrophages.

We are grateful to Mr Bo Nilsson for skilful technical help. This study was supported by a grant from the Swedish Work Environment Foundation.

\section{References}

' Bohning DE, Atkins HL, Cohn SH. Long-term particle clearance in man: normal and impaired. Ann Occup Hyg 1982; 26:259-71.

2 Bailey MR, Fry FA, James AC. The long-term clearance kinetics of insoluble particles from the human lung. Ann Occup $\mathrm{Hyg}$ 1982;26:273-90.

2a Philipson K, Falk R, Camner P. Long-term lung clearance in humans studied with Teflon particles labelled with ${ }^{\text {s1 }} \mathrm{Cr}$. Exp Lung Res (in press).

${ }^{3}$ Morrow PE, Gibb FR, Johnson L. Clearance of insoluble dust from the lower respiratory tract. Health Phys 1964;10:543-55.

4 Mercer TT. On the role of particle size in the dissolution of lung burdens. Health Phys 1967;13:1211-21.

s Moss OR, Kanapilly GM. Dissolution of inhaled aerosols. In: Willeke K, ed. Generation of aerosols and facilities for exposure experiments. Ann Arbor: Science Publishers Inc, 1980:105-24.

- Raabe OG. Deposition and clearance of inhaled aerosols. In: Witschi $\mathbf{H}$, Nettesheim $\mathrm{P}$, eds. Mechanisms in respiratory toxicology. Vol 1. Boca Raton, Florida: CRC Press, Inc, 1982:27-76.

' Lundborg M, Lind B, Camner P. Ability of rabbit alveolar macrophages to dissolve metals. Exp Lung Res 1984;7:11-22.

- Hoslam PL, Turton CW, Heard B, et al. Bronchoalveolar lavage in pulmonary fibrosis: comparison of cells obtained with lung biopsy and clinical features. Thorax 1980;35:9-18.

- Myrvik QN, Leake ES, Farris B. Studies on pulmonary alveolar macrophages from the normal rabbit: a technique to procure them in a high state of purity. $J$ Immunol 1961;86:128-32.

${ }^{10}$ Lundborg M, Holma B. In vitro phagocytosis of fungal spores by rabbit lung macrophages. Sabouraudia 1972;10:152-6.

" Jensen MS, Bainton DF. Temporal changes in pH within the phagocytic vacuole of the polymorphonuclear neutrophilic leukocyte. J Cell Biol 1973;56:379-88.

12 Ohkuma S, Poole B. Fluorescence probe measurement of the intralysosomal $\mathrm{pH}$ in living cells and the perturbation of $\mathrm{pH}$ by various agents. Proc Nat Acad Sci USA 1978;75:3327-31.

13 Mandell GL. Intraphagosomal pH of human polymorphonuclear neutrophils. Proc Soc Exp Biol Med 1970;134:447-9.

14 Bergström R. Acute pulmonary toxicity of manganese dioxide. Scand J Work Environ Health 1977;3:suppl 1.

is Morrow PE, Gibb FR, Gazioglu KM. A study of particulate clearance from the human lungs. Am Rev Respir Dis 1967;96:1209-21. 